Utah State University

DigitalCommons@USU

\title{
$5-2013$
}

\section{The Effects of Parent Training on Knowledge of Transition Services For Students with Disabilities}

John Young

Utah State University

Follow this and additional works at: https://digitalcommons.usu.edu/gradreports

\section{Recommended Citation}

Young, John, "The Effects of Parent Training on Knowledge of Transition Services For Students with Disabilities" (2013). All Graduate Plan B and other Reports. 304.

https://digitalcommons.usu.edu/gradreports/304

This Creative Project is brought to you for free and open access by the Graduate Studies at DigitalCommons@USU. It has been accepted for inclusion in All Graduate Plan B and other Reports by an authorized administrator of DigitalCommons@USU. For more information, please contact digitalcommons@usu.edu.

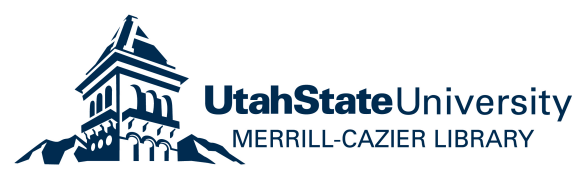


THE EFFECTS OF PARENT TRAINING ON KNOWLEDGE OF TRANSITION

SERVICES FOR STUDENTS WITH DISABILITIES

by

JOHN YOUNG

A creative project submitted in partial fulfillment of the requirements for the degree

of

MASTERS Of EDUCATION

in

Special Education

Approved

Robert Morgan $\mathrm{PhD}$

Major Professor

Tim Riesen PhD

Committee Member

Kimberly Snow MEd

Committee Member

UTAH STATE UNIVERSITY

Logan Utah

2013 


\author{
ABSTRACT \\ The Effects of Parent Training on Knowledge of Transition Services \\ for Students with Disabilities \\ by \\ John Young, Masters of Education \\ Utah State University, 2013
}

Major Professor: Dr. Robert Morgan

Department: Special Education

A major focus in secondary education for many students with disabilities is to improve independent living skills and prepare students with the vocational skills needed to participate in competitive employment. Yet the outcomes remain poor for these students when compared with their nondisabled peers. One factor accounting for poor outcomes is lack of preparation for the parents. The purpose of this study was to examine the impact of parent training on knowledge of transition agencies and supports for students with disabilities. The study was intended to connect parents with needed agencies and supports for the purpose of improving transition outcomes for students with disabilities. Two types of training were compared: (a) exposure to a brochure with transition information, and (b) brochure exposure plus 60-min of small group training conducted by the researcher. The Brochure Only group consisted of 13 participants while the Brochure Plus Training Group had 16 participants. First, parents individually took a pretest to determine their knowledge of transition agencies and support services. Parents 
in the Brochure Only group showed a mean pretest score of 1.38 out of 10.0. Parents in the brochure plus training group showed a mean pretest score of 1.13 out of 10.0. Second, parents were given a copy of a transition brochure that included contact numbers and web site information for each agency discussed during the training. Parents in the brochure group reviewed the brochure information for up to $60 \mathrm{~min}$. Parents in the brochure plus small-group training met with the researcher who described each agency and service. Third, immediately following the training, parents individually took the same test as a posttest. The brochure only group showed a mean posttest score of 3.0 out of 10.0 , the mean difference score being 1.62 when compared to the pretest. The brochure plus training group showed a mean posttest score of 7.31 out of 10.0 , the mean difference score being 6.19 when compared to the pretest. Finally, all participants were directed to select an agency from the brochure and set a goal to make contact with that agency. After 30 days, the researcher contacted all of the participants to verify if the contact was made. Results for the brochure plus training group showed that nine out of 16 parents made contact with a community agency. Results for the brochure only group showed that zero out of 13 made contact with a community agency. Parents who participated in the Brochure Plus Training showed a larger increase in their posttest knowledge score and were more likely to make contact with a community agency than parents in the Brochure Only group. 


\section{Introduction}

Hendricks and Wehman (2009) describe successful transition of students with disabilities as a collaborative effort involving students, parents, teachers, and vocational rehabilitation providers. This process requires coordinated effort and participation of team members for successful outcomes. Perhaps the most important team members, aside from the student in transition, are the parents because their advocacy, support, and encouragement can create a successful transition for their young adult from school to adult living (Lindstrom, Doren, Metheny, Johnson, \& Zane. 2007).

A barrier in the transition process occurs when students with disabilities and their parents are left alone to navigate this process by themselves. Professionals can help parents and students by informing them of available services and what those services can offer the student. But even when information is provided, often in transition planning meetings, parents may still not understand the information related to the student needs (Lindstrom et al., 2007) and professionals fail to connect families with needed community agencies. Through a collaborative transition process, parents and students can communicate the student's preferences, hopes, and needs. In return, professionals can provide important information to families through sharing and teaching about successful transition of students with disabilities to adult life. Family participation is not only an effective practice, but also the Individuals with Disabilities Education Act emphasizes family involvement in all IEP development, including transition.

Teachers have the opportunity to teach parents and students what school and community agencies are available and what services and supports they provide (Utah Parent Center, 2009). Through the teaching process, professionals can also provide 
contact information such as phone numbers and e-mail addresses of school programs and community agencies, to assist parents in making contacts. Teachers can invite representatives from these agencies to participate in transition planning meetings. Given a concerted and targeted teaching effort, informed parents and students can locate services and supports available in a number of public and private organizations, agencies, and programs (Lindstrom et al., 2007).

\section{Literature Review}

The review of existing research on parent training in transition was conducted using ERIC via EbscoHost. Articles for inclusion addressed parent training by professionals of the transition process and its effects on transition. One search included the key terms transition to adulthood, special education, and parent training. This search identified 13 studies but none were directly related to parent training in the transition of youth with disabilities to adulthood. A second search included the terms parent training, transition from school to adulthood, and people with disabilities. This search identified two studies but neither were directly related to parent training and improved knowledge about transition. A broadened search included articles that stressed the importance of parent participation in the transition process. A search with the terms adolescents, parents, and transition planning produced 69 results of research articles. Again, no research was found that measured the effects of parent training, but the articles selected for review below addressed the role of family in the transition process for improved outcomes.

A study by Lindstrom et al. (2007) conducted transition-related research through in-depth interviews with 133 individuals, including young adults with disabilities, high 
school teachers and other school staff, parents, vocational rehabilitation counselors, and employers. Researchers conducted interviews with parents to understand their perceptions of the transition process. Through the interviews, researchers identified transition practices that led to successful outcomes. Parents consistently noted the need for youth and families to receive information about community-based agencies and other specialized programs for adults with disabilities. Parents identified, as one of the top four priorities, utilizing transition services and post school supports by connecting students with the appropriate services and supports found in community agencies.

In a similar study, Hetherington et al. (2010) studied the "lived experiences" (p. 163) of adolescents with disabilities and their parents in transition planning. They conducted in-depth interviews with 13 youth with a variety of disabilities between the ages of 15 and 20. Also, parents of the students were invited to participate in a focus group with the interviewers. Six mothers and three fathers participated, representing nine of the students selected to be interviewed. During two 90-min focus groups, parents shared their experiences from participating in the transition process while a facilitator took detailed notes. Later, the facilitator shared key points back to the parents for validation that their perspectives had been adequately captured. Results indicated that parents consistently felt like outsiders in the transition process and when they received information from schools, they felt it was "too little, too late" (p. 170). These findings correspond with Lindstrom et al. (2007) because they demonstrate the importance that parents place on possessing relevant information and becoming active participants.

In a study by Lindstrom, Doren, Metheny, Johnson, and Zane (2007), 13 young adults with identified learning disabilities, their parents, and various school staff 
participated in in-depth interviews that measured the effects of family participation in the transition process on post-school employment outcomes. Interviewers conducted a total of 59 interviews, including 18 with the parents of student participants. All parent interviews occurred at their place of residence. Results identified $53 \%$ of parents in the study as providing higher level of involvement and the remaining $47 \%$ as providing lower levels of involvement. The study further used three labels to characterize family support levels as (a) advocates, (b) protectors, and (c) removed (p. 358). Advocate parents were described as those playing an active role in planning and support in the lives of their young adults. Youth participants with advocate parents tended to transition more successfully to work, earning higher wages and/or higher skill occupations, while youth participants with protective or removed parents did not fare as well.

Summary of research. This research shows that parents often feel like outsiders in transition and are not receiving the information they need for their children with disabilities to transition successfully to adult life. Or, if they are receiving information, they are not being guided in how to use it to actively seek services described in the information. This lack of information leads to confusion about transition. Parents expressed the need for more information presented in a clear format to better understand the transition process. Successful transition of students with disabilities requires that parents receive this information and research shows it is not occurring consistently. In the final study reviewed, Lindstrom et al. (2007) found that when parents were informed and were able to act as advocates for their children, opportunity for successful outcomes in areas such as employment increased. Parents need specific training about services and supports available for people with disabilities, how to make contact, and how to become 
advocates to receive those services.

\section{Purpose Statement and Research Question}

The purpose of this study was to assess the effects of parent training on knowledge about Granite School District and community agency services. Two types of training are being compared: (a) information presented to parents on a printed brochure, and (b) information presented to parents on a printed brochure plus $60 \mathrm{~min}$ of smallgroup parent training. Thus, the research questions are:

1. Given parents of students with disabilities randomly assigned to one of two groups, will exposure to information on a brochure or the brochure plus a $60-\mathrm{min}$ parent training increase parent knowledge of Granite School District and community agency services available to students with disabilities, as measured by percentage of responses correct on a posttest?

2. Which form of training produces better results for parent participants: exposure to information on a brochure or brochure plus small group training?

3. Will either form of training lead to parents' contacting school district services or community agencies as measured in 30-day follow up telephone calls?

\section{Method}

\section{Participants}

Parents were selected as participants who have a child with an identified disability and whose child receives special education services from Granite School District. A parent was defined as any person who is considered the primary caregiver of the child with a disability. The child and caregiver had to live at the same residence. Foster 
parents, court-appointed guardians, adopted parents, and biological parents could all qualify as participants. They could be either male or female and can be from any ethnic background. They must have had a child with a disability that was currently of transition age between 15-18 years and enrolled in a secondary school. Participants were selected from two neighboring secondary schools within the same school district. They included parents of transition age students with mild disabilities (e.g., specific learning disabilities, mild/moderate intellectual disability, high-functioning autism spectrum disorder) and parents of students with severe disabilities (e.g., severe intellectual disability, lowfunctioning autism spectrum disorder, multiple disabilities). To assure that participants understood the procedure and that effective communication during the research occurred, participants were required to use English as the primary language in their home.

Guardians who met the previously stated definition of parent could be included as participants. Guardians could only be included if English was the primary language spoken in their home because there was a teaching phase as part of the procedure. Participants needed to speak and comprehend English proficiently to assure that all information presented was understood. It was important that all participants lived in the same school district because part of the teaching phase in the procedure taught about transition services specific to Granite School District. Guardians were excluded from participation who did not meet the previously stated definition of parent.

The researcher contacted special education teachers in each of the two schools. The teachers were asked to identify and contact parents/guardians of students in their school who met the criteria for participation. These parents were asked to contact the researcher if they were interested. The initial pool of parents contacted by their teachers 
was 36. Parents were randomly assigned to the Brochure Only or Brochure Plus Training cohorts. Parents were given different descriptions of the research project depending on group membership. Of 17 parents assigned to the Brochure Only group, 13 attended individual sessions. Of 19 parents assigned to the Brochure Plus Training group, 16 attended small-group training sessions. Parent participants included 23 females and six males, consisting of 27 Caucasians and two Hispanics. Twenty-one parents had children with mild disabilities (specific learning disabilities, high-functioning autism spectrum disorder, mild intellectual disability). Eight parents had children with severe disabilities (moderate/severe intellectual disability, multiple disabilities, low-functioning autism spectrum disorder). All parents represented low to middle-income families living in a suburban area of a Western U.S. city with a population of over 1 million people.

\section{Setting}

A conference room in the researcher's school setting served as the research setting. Brochure Only parents were allowed to use the room to review brochure information. For Brochure Plus Training participants, the researcher sat on one side of the conference room table while the participants sat directly across the table. This allowed all participants a clear view of any visual aides used by the researcher, and allowed all participants to talk directly to the researcher.

\section{Dependent Variable}

The dependent variable in this study was the knowledge based on test scores that parents of students with disabilities possessed about transition services. Parent knowledge of transition services was defined as the written responses to test questions by parents regarding their knowledge of Granite School District transition services and community 
agency services, what support those services provide, and contact information to make connections with those services.

Response measurement. The knowledge that parents currently possessed about transition services was measured by the number of questions answered correctly through the administration of a pretest (see Appendix A). The researcher served as the primary data collector. Upon arrival, participants received a copy of the pretest and were informed that the researcher would like to find out what knowledge they had about transition services. The questions were read aloud by the researcher to assure that all participants comprehended the meaning. The pretest included 10 questions related to transition services. Five questions on the pretest were related to transition services provided by Granite School District, and five questions were related to transition services provided by community agencies. Questions were related to services an agency provided, how to contact the agency, or how to qualify for those services. All questions on the test came from information outlined in the transition brochure and the training session. The posttest was identical to the pretest but with questions randomized to produce a different order.

\section{Procedures}

Recently, Granite School District placed more focus on transition services provided to students with disabilities with the goal of improving transition outcomes of independent living and vocational placement. To help in the planning process, a professional learning community (PLC) was created that included special education teachers, school counselors, career counselors, and employment specialists. These professionals wanted to create a product that could be used as a guide in both training parents and students about transition services and as a guide to help create effective 
transition plans. The PLC created a brochure that included Granite School District transition services and community agencies and descriptions of the services they provide. The brochure also included contact information, such as telephone numbers and email addresses, to help establish connections between families and transition service providers. Before using the brochure, it was examined by a committee of district administrative workers including the associate director of special education in Granite School District. The committee made recommendations for improvement and the final edits. The brochure was used as an aid for parent trainings in this research.

Two types of training were compared across groups of participants: (a) exposure to a brochure with transition information, and (b) brochure exposure plus 60-min of small group training conducted by the researcher.

Brochure only. Following the pretest, the researcher provided the Granite District Transition Services brochure (see Appendix B) that includes contact numbers and web site information for numerous agencies. The researcher stated: "Here is the Granite District Transition Services brochure. We believe this includes all evidence you will need to find the transition services your child will need before and after leaving school. You may look at this for up to 60 min if you want. Then I need to give you a posttest."

If participants asked questions about the brochure, the researcher referred them to information in the brochure. If participants insisted on information from the researcher, he said he could talk to participants after the posttest. Following review of the brochure or after 60 min, participants took the posttest. Participants were allowed to use the brochure and any notes taken to answer the questions on the posttest. 
Brochure plus training. Following the pretest, the researcher provided training to groups of 2-5 parents for $60 \mathrm{~min}$. The researcher stated: "Here is the Granite District Transition Services brochure. We believe this includes all evidence you will need to find the transition services your child will need before and after leaving school." Using the brochure as the guide, the instruction then described Granite School District and community agency transition services available for students with disabilities. Participants could ask any questions they had during the instruction time. Granite School District transition included information about (a) Granite Transition (G.I.F.T.S. and G.A.T.E.), (b) Jones Center, (c) Jones Center Vocational Academy (JCVA), (d) Granite Technical Institute (GTI), (e) Career and Technical Education (CTE), (h) Hartvigsen School, and (i) Granite Peaks School. Community agencies included information about (a) Vocational Rehabilitation (VR), (b) Social Security Benefits (SSI), (c) Support Work Independence (SWI), (d) Division of Services for People with Disabilities (DSPD), (e) guardianship questions, (f) Utah Parents Center, (g) Independent Living Center, (h) Department of Workforce Services (DWS), (i) university and college disability resource centers, and (j) Salt Lake Community College School of Applied Technology.

The researcher discussed each school service and community agency in the order it was outlined in the brochure, beginning with school transition services and ending with community agency services. Immediately following the training, participants individually took the posttest. Participants were allowed to use the brochure and any notes taken to answer the questions on the posttest.

Follow-up. Both Brochure Only and Brochure Plus Training participants were given a goal page (Appendix D) and asked to identify one school transition service or one 
community agency that they would contact before the end of a 30-day time period.

Participants then wrote down the agency that they were most interested in contacting. The researcher then invited each participant to make contact with the identified agency. The researcher informed participants that a follow-up call would be made in 30 days. At the identified date, the researcher called each parent to verify whether they had made contact with the transition agency. If participants indicate "yes", the researcher asked additional follow-up questions regarding the person contacted, information received, questions answered, and plans set in place to apply for/receive services. The follow-up questions served to ascertain the veracity of the contact.

\section{Treatment Integrity}

To ensure that parent training was similar across groups of 2-5 parents in the Brochure Plus Training group, an independent observer attended four out of six sessions. The observer followed a checklist to score whether the researcher read the same script, administered consistent training on key aspects (i.e., greeted parents, asked about parents' children in transition, described rationale for training: to provide parents information so that they can independently seek services, explained the diagram on Granite School District level of support, described each Granite School District service, described each community service, reviewed contact information on at least one relevant agency or service, asked if parents have questions, provided posttest). See the treatment integrity checklist in Appendix C. The independent observer scored each checklist item as "yes" or "no", and computed a percent of yes divided by total items. This percentage was included in the results to show high levels of treatment integrity. The independent observer scored $100 \%$ of the responses as "yes" across all four training sessions observed. 


\section{Data Analysis}

First, mean pretest and mean posttest scores were computed for each group. Second, the data for each participant was compiled in a pretest/posttest pair for comparison of the scores. A difference score was computed as a measure of the anticipated increase in the posttest score. The difference scores for participants in the Brochure Plus Training were compared against the difference scores for participant in the Brochure Only group. Third, the follow-up data was computed as a percentage of parents who responded "yes" for making contact with a transition service provider. Names of service providers were compiled. Anecdotal responses from participants were recorded on whether the brochure and training session were helpful and key in changing any perspectives regarding transition.

\section{Results}

\section{Pretest and Posttest Comparison Data for the Brochure Only and Brochure Plus Training Groups}

Figure 1 presents mean pretest and posttest scores for the Brochure Plus Training and Brochure Only groups. The mean pretest score for the Brochure Plus Training group was slightly less than the mean pretest score for the Brochure Only group (1.13 items correct out of 10 versus 1.38 correct). Scores ranged from 0 to 3 correct for both the brochure plus training and brochure only groups. The mean posttest score for the Brochure Plus Training group was 7.31 for the Brochure Plus Training group, compared to 3.00 for the Brochure Only group. 


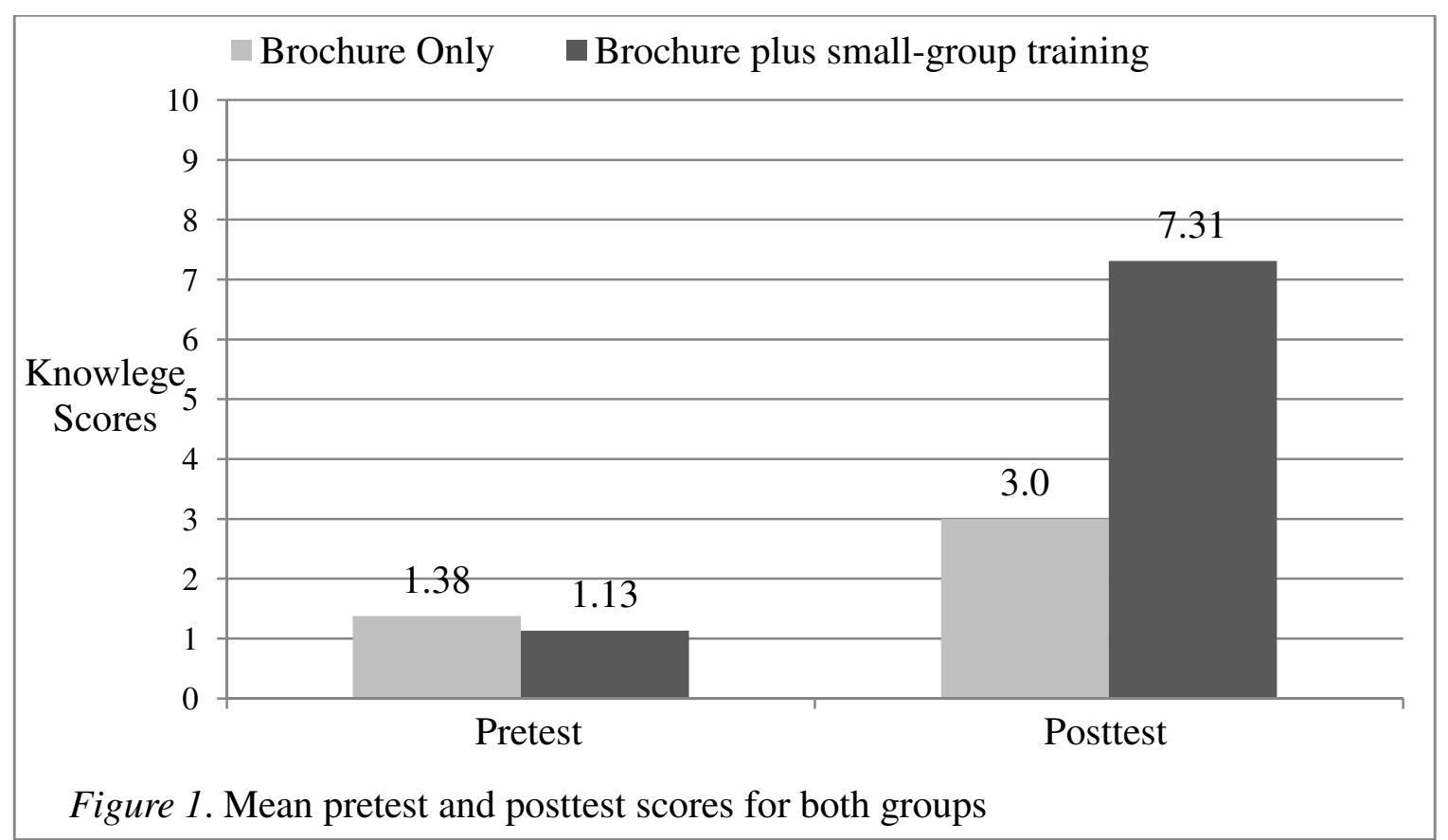

\section{Mean Difference Scores}

Figure 2 presents mean difference scores for the two groups. Mean difference scores for the Brochure Plus Training and Brochure Only groups were 6.19 and 1.62, respectively.

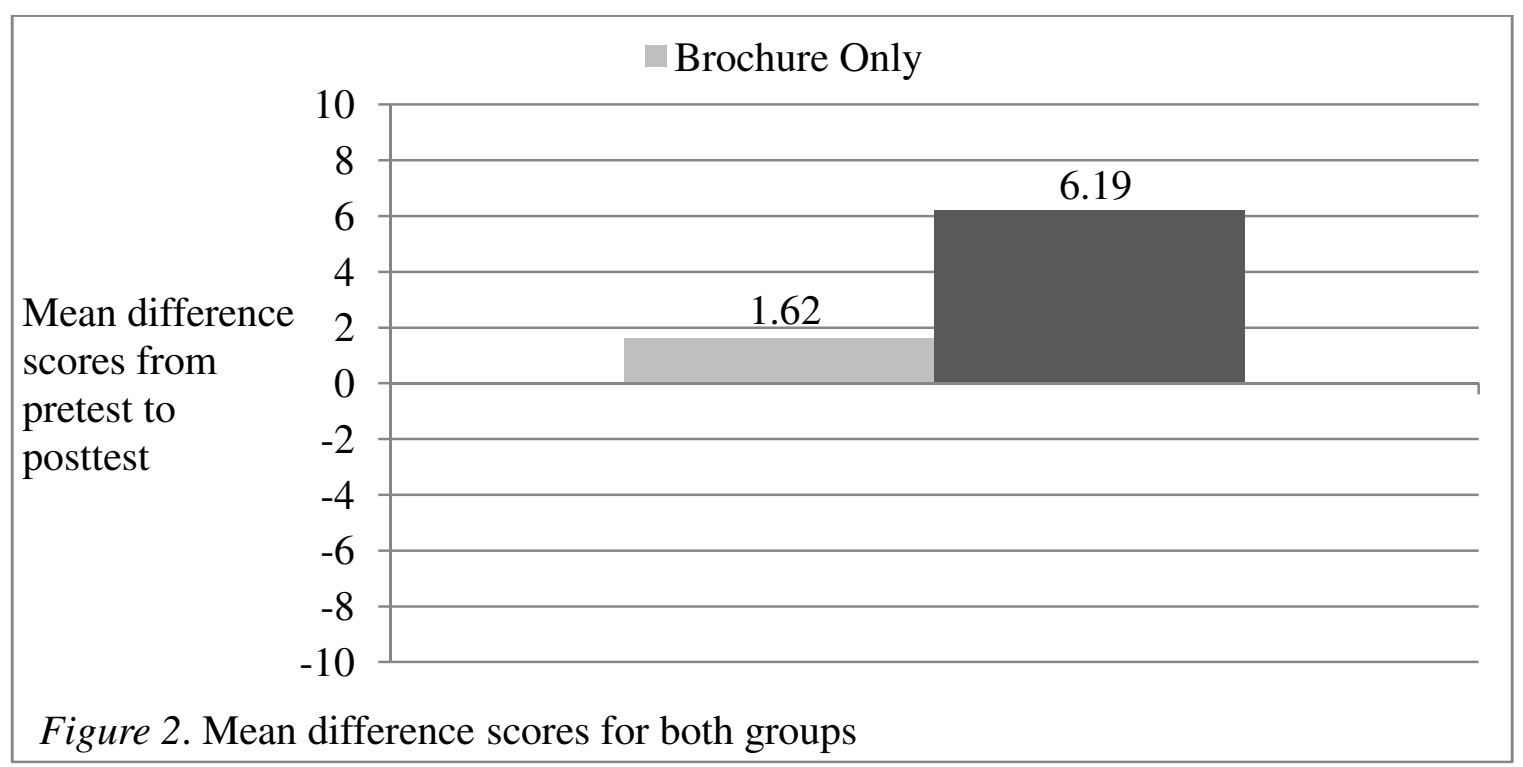

For the Brochure Plus Training group, scores ranged from 4 to 10. Three parents scored 10 out of 10, including one who scored 0 on the pretest. For the Brochure Only group, 
scores ranged from 1 to 7 . Nine of 13 parents in the Brochure Only group had difference scores of 0 or 1.

\section{Anecdotal Data}

At the end of each training session, the researcher discussed with participants their opinions of the training and the brochure. A notebook was also left on the table for written comments and opinions of their experience. Participants of the Brochure Only sessions in general seemed appreciative of the information provided in the brochure. One participant commented that, "it was good information and a good starting place for my own investigation". Another participant from the Brochure Only group indicated she felt overwhelmed by all the information provided in the brochure and nervous to make contacts to service providers by phone. The conversation continued after the posttest. Websites addresses were highlighted on the brochure and she was encouraged to investigate agencies on the internet. We investigated the "Columbus Community Center" web site together. We read the mission statement of the agency and all the services they provided people with disabilities. Many participants in the Brochure Only trainings verbally expressed appreciation for the information provided but none made written comments in the notebook. Brochure Only participants did not take advantage of the entire 60 min allowed for independent review of the brochure. Instead, they took only an estimated 10-20 min to review the contents of the brochure. Participants in the Brochure Only group required a lot of time to take the posttest. Several participants expressed frustration from the inability to find answers for the posttest quickly. A final participant expressed frustration for not being able to ask questions while examining the brochure and or concerning the posttest. Many participants from the Brochure Plus Training 
expressed verbal appreciation for the brochure and the explanation of all the services. Most finished the posttest in short amount of time and continued to ask questions after the training concluded. This resulted in parent trainings lasting as long as 90-min. Many questions were specifically related to what services would be good for their child.

Several participants also provided written comments. One wrote, "this training gave me a lot of information and it was very helpful. I enjoyed it. I believe this information should be given sooner; maybe the $7^{\text {th }}$ grade". Another participant wrote, "I appreciated the comprehensive information, the friendly atmosphere, and the helpful answers to all my numerous questions. I am still overwhelmed, but much more knowledgeable about where to start". Another written comment said, "I found it very helpful and now I know what to do for my other child with a learning disability as well". Another wrote, "I really am glad to participate in this class. I've learned more about rehabilitation and help for students with any kind of disability. I definitely support this program". A final participant wrote, “This really helps with understanding and supplying resources at your fingertips".

\section{Results for 30-Day Follow-up Contacts}

Brochure Plus Training Group. Two participants in this group could not be reached by phone for the follow-up contact. After three attempts by phone, the researcher sent e-mails to the two participants inquiring if contact had been made. No responses came. Therefore, no response could be recorded. Nine out of 14 , or $64.28 \%$ of participants from the brochure plus training group made a contact with a school service or community agency. Two participants contacted Vocational Rehabilitation. Both were excited about the information provided and eager for their student to participate. Two participants contacted the Division of Services for People with Disabilities. Both 
participants indicated their questions about supported employment were answered and began filling out applications to receive services. Two participants contacted Granite Transition. One indicated their questions were answered and their child would be attending Granite Transition Services. The other participant indicated she was told the program was "not a good fit" for their child. No further information of alternate programs was provided. One participant contacted the Columbus Community Center and indicated that all her questions were answered but she didn't feel it was "the right program" for her child. Four participants contacted the Utah Parents Center regarding questions about guardianship. Both were pleased with the information and felt it was important to begin the process.

Brochure Only Group. Four participants in this group could not be reached by phone for the follow-up contact. After three attempts by phone, the researcher sent emails to the four participants inquiring if contact had been made. No responses were forthcoming. Zero out of 9 participants that received the Brochure Only reported a contact with a school service or community agency.

\section{Discussion}

The researcher anticipated this study would reveal that parents are in need of training about transition services offered to students with disabilities. Through a sequence of pre- and posttests, I demonstrated that many parents were not well informed about transition services and that direct parent training increased their knowledge. The mean difference scores clearly demonstrated that it is not enough to simply provide parents with a brochure. Some participant scores in the Brochure Only group showed no improvement between the pretest and posttest. 
Parents were eager to talk about their children and share information. They shared what community and school services their children currently received, and what transition services were most needed for future success. During the brochure plus training sessions, the researcher used this valuable information to personalize the training for participants. They were able to ask questions that related directly to their students. Interaction between the researcher and the parents helped identify which agencies and services on the brochure were of most value to their child and the specific support the agency could provide to their child. Parents were given a highlighter and were directed to highlight on the brochure information of value for their child. Through the training, parents learned the meaning of key phrases used in the brochure; post high transition services, post secondary education, supported employment, supported living, etc. Participants in the Brochure Plus Training groups received valuable information presented in an organized manner and had their specific questions answered. These participants showed a higher increase in their knowledge of transition services available to their students. Participants in the Brochure Only group also provided valuable information to the researcher about the transition needs of their child. The result was no increase or a minimal increase of parent knowledge about transition services available to their student. Also, as parents in the Brochure Plus Training group received information, contacts were made to connect students with disabilities to community services. These participants discussed services directly related to their child and how specific services would benefit them. They highlighted these services of interest and set a goal to contact the agency. They were coached on what questions they might ask, what agency in the brochure might be of most value, and what specific services the child might receive. 
Many of these parent participants in the Brochure Plus Training groups became stronger advocates for their children by contacting a school service or community agency. The participants in the Brochure Only groups were also asked to identify an agency and set a goal to make a contact. These participants reviewed the brochure independently with no valuable information provided through training. There was no specific coaching provided about what questions to ask during the contact. Also, there was no guidance for participants to agencies that might be of most importance to their student. None of these participants followed through with their goal to contact an agency. This research demonstrated that the Brochure Plus Training intervention increased parent knowledge about transition services more than the brochure only intervention and increased the chances of parents making contact with community agencies.

A limitation of this research is that only English speaking parents participated. Future research in this area should include multicultural factors and the impact this research would have on culturally diverse participants. Also, this study includes only parents of students of 18-22 years. A wide age range of students, both older and younger than 18-22, are in need of transition planning assistance. Parents of those students should be considered for inclusion in future research.

Finally, effective transition of students with disabilities requires effective and ongoing communication between parents, students, and professionals. This research was limited to one training session and a follow up call. This was not enough time to effectively plan the transition of a student from school to independent living. Future research should include transition progress over longer periods of time with more than one follow up contact between teacher and parent. This study did not reveal if any parent 
contacts led to receiving services for students with disabilities. Research with ongoing interaction between parents and teachers could lead to better transition outcomes.

This research demonstrated that teachers play an important role in the transition of students with disabilities. Educators need to perform at a higher level providing specific information about school services and community agency transition services to parents. It demonstrated that parents are not receiving transition information and if they do, it is not received early enough in the transition process. Professionals need to prepare and become informed about transition services and present information to parents in an organized way that will lead to increased knowledge of transition. 


\section{REFERENCES}

Hendricks, D. R., \& Wehman, P. (2009). Transition from school to adulthood for youth with autism spectrum disorders: Review and recommendations. Focus on Autism and Other Developmental Disabilities, 24(2), 77-88.

Hetherington, S.A., Durant-Johnes, L., Johnson, K., Nolan, K., Smith, E., Taylor-Brown, S., \& Tuttle, J. (2010). The lived experiences of adolescent with disabilities and their parents in transition planning. Focus on Autism and Other Developmental Disabilities, 25(3), 163-172.

Lindstrom, L., Doren, B., Metheny, J., Johnson, P., \& Zane, (2007). Transition to employment: Role of the family in career development. Exceptional Children, $73(3), 348$.

Lindstrom, L., Paskey, J., Dickinson, J., Doren, B., Zane, C., \& Johnson, P. (2007). Voices from the field: Recommended transition strategies for students and school staff. Journal for Vocational Special Needs Education, 29(2), 4-15.

Utah Parent Center. (2009). Utah parent center handbook: From no where to know where. Retrieved from http://www.utahparentcenter.org 
Appendix A

Pretest: Transition Training

1. What school program would you contact if your child is not graduating at the end of their senior year and is in need of specific training for independent living, community access, and vocational training?

2. What school program should you contact if your child is not graduating at age 18 but is interested in a program offering credit recovery after his/her senior year for students wanting to graduate?

3.What are three courses offered through Granite Technical Institute?

4. What Granite school district program offers vocational training and job sampling at community work sites for students with disabilities?

5. What school program offers individualized employability skills training and help for becoming employed?

6. What community resource can you contact for IEP help, guardianship questions, and advocacy needs for your child?

7. What community agency provides vocational education and job placement for people with disabilities?

8. Who does your child contact if he/she will be participating in post secondary education at a specific college, or technical training center and needs disability services such as, specific accommodations or assistive technology?

9. What post secondary education program in Salt Lake offers training for specific occupations and a shorter course of study than a traditional college program for a quicker entry into a career?

10. What program offers supported employment for people with severe disabilities for continued employment and training? 


\section{Post Test: Transition Training}

1. What community agency provides vocational education and job placement for people with disabilities?

2. Who does your child contact if he/she will be participating in post secondary education at a specific college, or technical training center and needs disability services such as, specific accommodations or assistive technology?

3. What school program offers individualized employability skills training and help for becoming employed?

4. What community resource can you contact for IEP help, guardianship questions, and advocacy needs for your child?

5.What are three courses offered through Granite Technical Institute?

6. What Granite school district program offers vocational training and job sampling at community work sites for students with disabilities?

7. What post secondary education program in Salt Lake offers training for specific occupations and a shorter course of study than a traditional college program for a quicker entry into a career?

8. What program offers supported employment for people with severe disabilities for continued employment and training?

9. What school program would you contact if your child is not graduating at the end of their senior year and is in need of specific training for independent living, community access, and vocational training?

10. What school program should you contact if your child is not graduating at age 18 but is interested in a program offering credit recovery after his/her senior year for students wanting to graduate? 
Appendix B
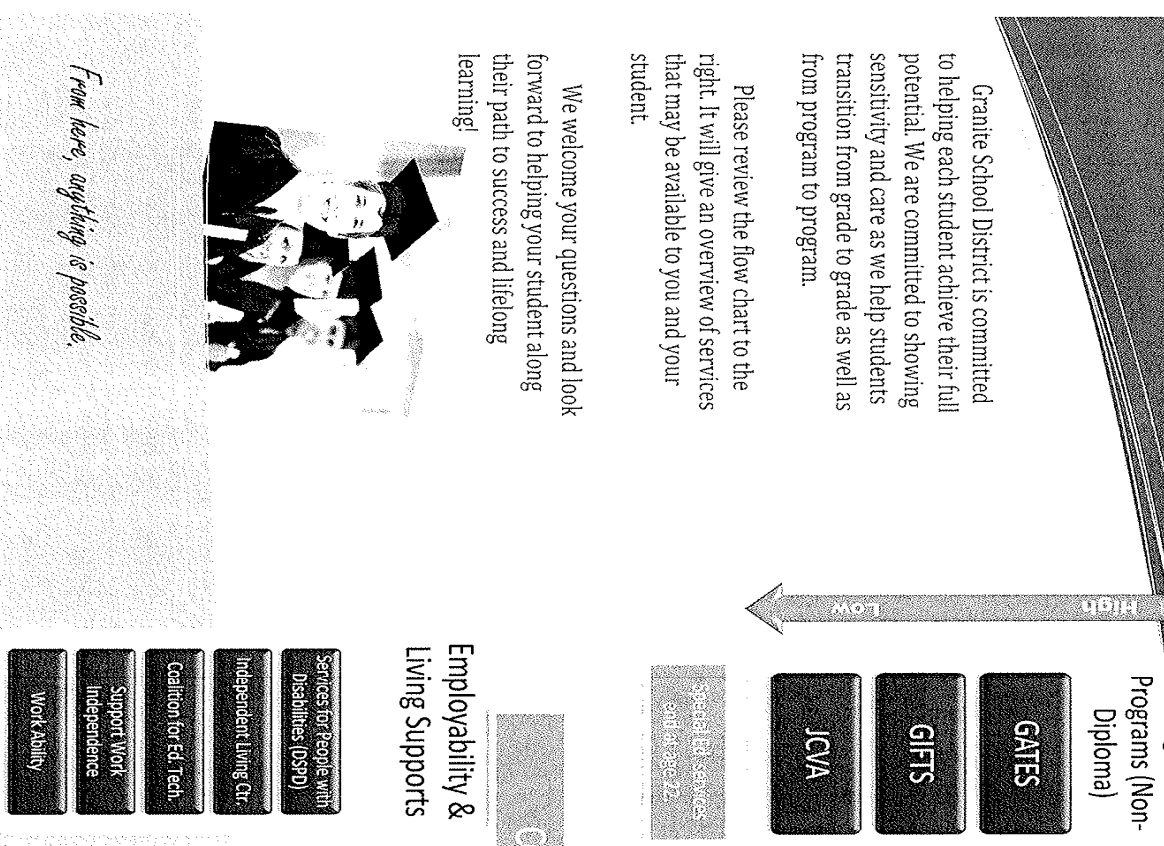

5

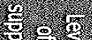

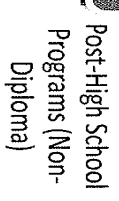

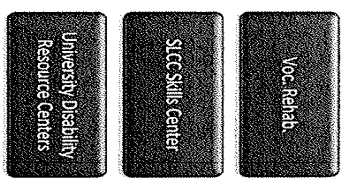

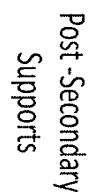
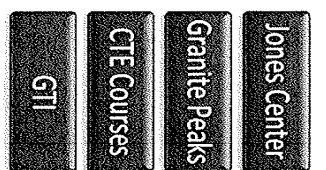

mit

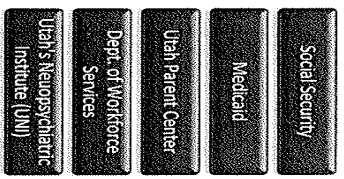

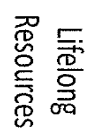
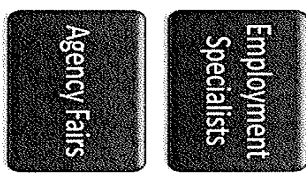

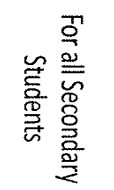

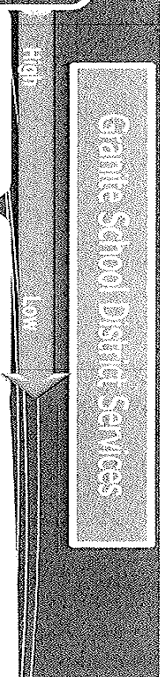



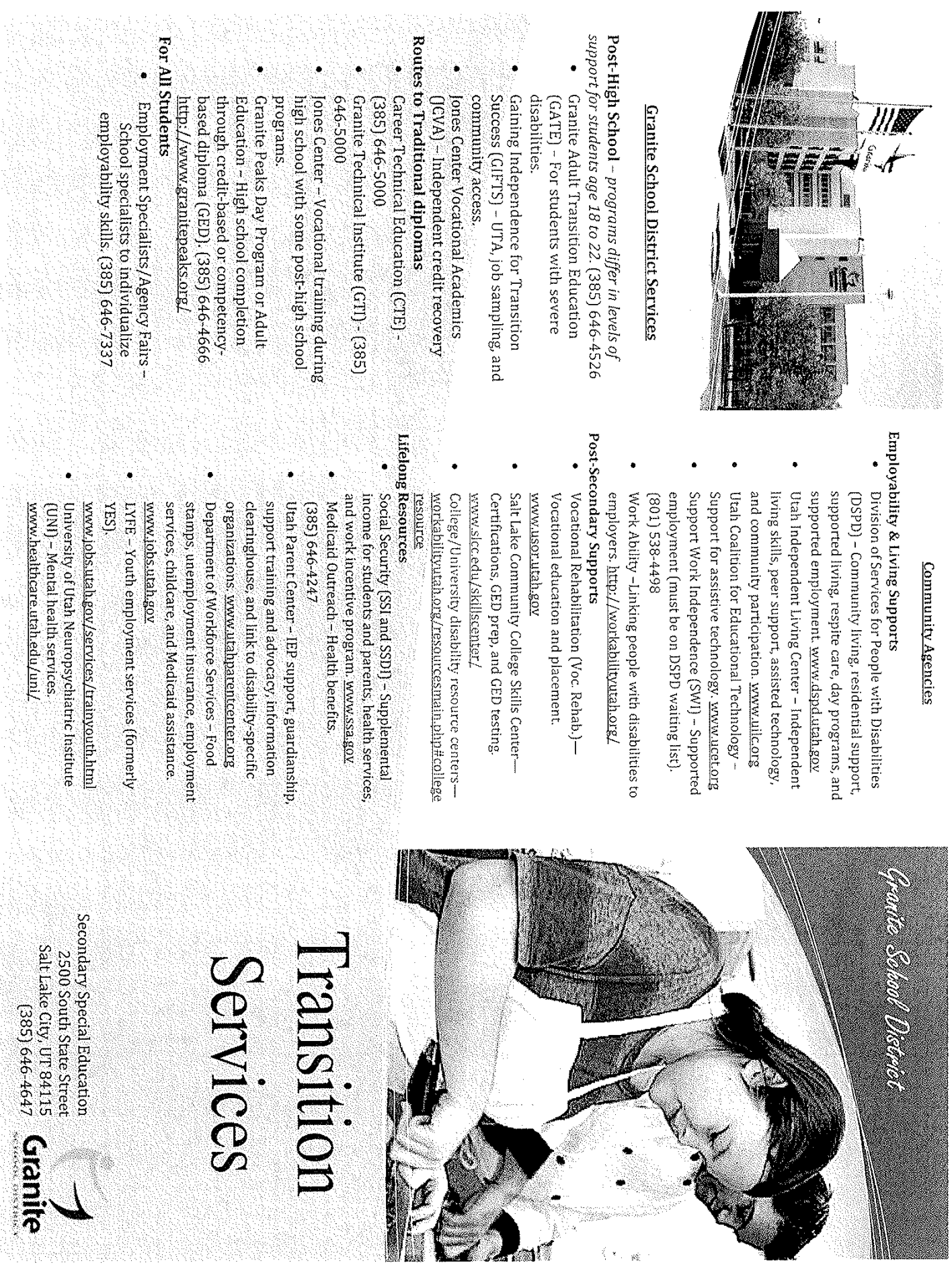


\section{Appendix C}

\section{Treatment Integrity Checklist}

1. Greet Parents.

2. Ask about children in transition.

3. Describe rationale for training.

4. Provide pretest.

5. Collect pretest results.

6. Explain diagram on school district level of support.

7. Describe each Granite School District service.

8. Describe each community agency.

9. Review contact information for a relevant agency or service.

10. Provide posttest.

11. Collect posttest results.
Yes ( ) No ( )

Yes ( ) No ( )

Yes ( ) No( )

Yes ( ) No( )

Yes ( ) No ( )

Yes ( ) No( )

Yes ( ) No ( )

Yes ( ) No ( )

Yes ( ) No ( )

Yes ( ) No ( )

Yes ( ) No ( ) 


\section{Appendix D}

\section{Goal Page}

My goal in the next 30 days is to contact the following agency (list name, contact person - if known, phone number, etc.): 